\title{
Examining Perceived Stereotype Threat among Overweight/Obese Adults Using a Multi-Threat Framework
}

\author{
Robert A. Carels Sarah E. Domoff Jacob M. Burmeister Afton M. Koball \\ Nova G. Hinman Alan K. Davis Marissa Wagner Oehlhof Michelle Leroy \\ Erin Bannon Debra A. Hoffmann \\ Department of Psychology, Bowling Green State University, Bowling Green, OH, USA
}

\section{Key Words}

Stereotype threat · Stigma consciousness · Obesity · Weight stigma · Group identity

\begin{abstract}
Objective: The Multi-Threat Framework accounts for potentially different forms of stereotype threat that differ in target (i.e., the individual or the group) and source (i.e., the self or others). This investigation examined how these different forms of perceived stereotype threat were related to concepts, such as group identity, stereotype endorsement, stigma consciousness, etc., among overweight and obese individuals. Method: 216 adults completed an online survey. Participants' mean age was 23.6 (SD 10.1; range 18-64) years and mean BMI was 31.6 (SD 7.5) $\mathrm{kg} / \mathrm{m}^{2}$. Results: Participants reported a history of feeling threatened by stereotypes related to weight. When reflecting on past experiences of perceived stereotype threat, participants reported greater levels of self/own stereotype threat compared to group stereotype threat. Level of stereotype threat was related to a number of personal characteristics (i.e., sex, BMI) and individual factors (i.e., group identity, stigma consciousness, fear of fat). Conclusion: Individuals who are overweight report a history of being threatened by negative stereotypes. The findings support the Multi-Threat Framework for stereotype threat based on body weight. Overweight individuals' susceptibility to stereotype threat may vary systematically depending on several factors. Future research should examine weight-related stereotypes' impact on cognitive and behavioral outcomes.

Copyright (c) 2013 S. Karger GmbH, Freiburg
\end{abstract}


Carels et al.: Examining Perceived Stereotype Threat among Overweight/Obese Adults Using a Multi-Threat Framework

\section{Introduction}

The experience of weight bias is pervasive and results in a variety of negative physical and psychological consequences [1-4]. A component of weight bias is the set of negative stereotypes about obese persons. Some of the most common stereotypes include the belief that obese individuals are lazy, unmotivated, and lack self-discipline [4, 5]. Given the strength and ubiquity of these stereotypes, it is plausible that obese individuals, similar to other stereotyped groups, may experience disrupted performance on relevant tasks when their actions could be seen as confirming negative stereotypes associated with being overweight. This experience is commonly referred to as stereotype threat $[6,7]$.

Over the past decade, stereotype threat has become one of the most widely studied topics in social psychology [8]. Previous research has consistently shown that individuals often perform poorly on stereotype-relevant tasks when they are reminded of the stereotype beforehand [7-9]. Although a large body of work confirms the reliability of stereotype threat effects (e.g., underperformance for women in math or science and racial/ethnic minorities in academics), questions remain about whether the phenomenon occurs for other stereotyped groups (e.g., obese individuals) and about the form that stereotype threat might take among these groups. Preliminary research suggests that stereotype threat can impact the behavioral intentions of overweight/obese adults [10].

Once conceptualized as a unitary construct, recent research indicates that stereotype threat may be a set of several distinct processes and phenomena [11]. To address this variability, Shapiro and Neuberg [6] proposed a Multi-Threat Framework consisting of multiple, qualitatively discrete forms of stereotype threat. See Shapiro and Neuberg [6] and Shapiro [11] for a detailed description of the Multi-Threat Framework. The Multi-Threat Framework accounts for potentially different forms of stereotype threat that differ in target (i.e., to whom one's actions will reflect upon: the self or group) and source (i.e., who will judge these actions: the self or others). To explain further, when the target of the threat is the group, group concept threat is the fear that poor performance will confirm (in the individual's own mind) that negative stereotypes about obese individuals are true in general (target: other; source: self). group reputation threat is the fear that poor performance will confirm (in the minds of others) that negative stereotypes about obese individuals are true in general (target: other; source: group). For example, if an obese individual is asked to complete a task requiring effort and motivation, she or he may fear that she or he might confirm a negative stereotype (i.e., being lazy) about obese people. In contrast, when the target of the threat is the self, self-concept threat is the fear that poor performance will confirm (in the individual's own mind) that negative stereotypes about obese individuals are true, specifically of the individual (target: self; source: self). Own-reputation threat is the fear that poor performance will confirm (in the minds of others) that negative stereotypes about obese individuals are true, specifically of the individual (target: self; source: group). For example, if an obese individual is asked to complete a task requiring effort and motivation, she or he may fear that others see her or him as lazy (i.e., she or he confirmed a negative stereotype about obesity targeted toward the self).

With the development of the Multi-Threat Framework, Shapiro [11] proposed that a number of factors are associated with the emergence of stereotype threat. One such factor is group identification, which is apparent when individuals perceive themselves as similar to other in-group members [for review see 12]. Generally speaking, the stronger an individual identifies with his or her group (i.e., other obese individuals), the more likely the individual is to fear confirming and supporting the negative stereotype about obese persons.

Similarly, the Multi-Threat Framework suggests that stereotype endorsement is a critical factor in the emergence of stereotype threat [11]. The more an individual believes (or trusts that others believe) that a stereotype is true (stereotype endorsement), the more likely he or 
Carels et al.: Examining Perceived Stereotype Threat among Overweight/Obese Adults Using a Multi-Threat Framework

she will be to experience stereotype threat. For example, if an obese individual believes that obese people are lazy and lack self-discipline, then he or she would be categorized as high in stereotype endorsement and would be expected to be more fearful of confirming that obese individuals are lazy through their actions (stereotype threat).

In support of the Multi-Threat Framework, Shapiro [11] demonstrated that group identification, stereotype endorsement, and the perceived target of threat varied across different stigmatized groups. For example, individuals who are members of racial/ethnic or religious minorities have greater group identification and less stereotype endorsement compared to individuals who are overweight or have a mental illness. In a subsequent study, Shapiro [11] demonstrated that individuals in high stereotype-endorsing as well as low identifying groups (i.e., overweight, mental illness) were more likely to view themselves, rather than their group, as the target of the threat. Finally, when individuals who were blind at birth (likely high group identifiers) were compared to those who became blind later in life (likely low group identifiers), those who became blind later in life were more likely to report that the self rather than the group was the target of the threat.

Consistent with the Multi-Threat Framework [11], the current investigation sought to further examine the different forms of stereotype threat that present in individuals who are overweight/obese. Preliminary findings show that individuals who are overweight or obese have lower group identification and greater stereotype endorsement than other stigmatized groups, such as racial or religious minorities [11]. As a result, they are more likely to perceive the self as a target of threat compared to the group. Thus, hypothesis one was that this sample of individuals who are overweight or obese would endorse perceiving threat from situations in which they themselves are the target of the stereotype more so than when their group (overweight people in general) was the target of the threat.

In addition, we intended to examine the relationship between perceived stereotype threat and factors that hypothetically could be associated with perceived stereotype threat among overweight/obese individuals. Hypothesis two is multi-faceted, examining factors that included the participants' level of group identity and stereotype endorsement, their BMI and gender, their level of awareness of negative stereotypes about the group (i.e., stigma consciousness), and their own anti-fat attitudes and self-esteem. Given earlier findings related to perceived stereotype threat and weight status, it was hypothesized that individuals' level of identification with overweight/obese as a group (group identification) would be related to higher levels of perceived stereotype threat. Similarly, it was hypothesized that participants' level of belief that stereotypes about overweight people are true (stereotype endorsement) would also be related to higher levels of perceived stereotype threat.

In addition, an individual, who embodies characteristics that are representative of a stigmatized group (i.e., higher BMI) or who possesses an attribute that increases the likelihood that they will be a target of weight-based bias and discrimination (i.e., female gender), may be exposed to more circumstances where stereotyped evaluations occur [4, 13]. Similarly, research suggests that discrimination may occur at lower weight levels for women than for men [4]. Therefore, we hypothesized that females and individuals with higher BMIs would be more likely to report experiencing stereotype threat.

Furthermore, the more an individual is aware about his or her stigmatized status (i.e., stigma consciousness [14]), the more susceptible he or she may be to experiencing stereotype threat. For example, Brown and Pinel [15] showed that inducing stereotype threat in a group of women, who also reported high levels of stigma consciousness, resulted in domain-specific performance deficits (i.e., lower scores on math tests). Therefore, we hypothesized that overweight persons who were more self-conscious about their stigmatized status would be more likely to report stereotype threat. 
Additionally, two potentially relevant factors to perceptions of stereotype threat are weight bias and self-esteem. First, contrary to other stigmatized groups, who are less likely to accept with-in group stereotypes, previous research suggests that overweight and obese people frequently hold strong anti-fat (i.e., anti-group) attitudes and, as indicated above, express higher levels of stereotype endorsement $[4,11]$. Therefore, we hypothesized that the more likely that an overweight/obese person is to make negative judgments about other obese individuals, the more likely they are to be aware that others are making stereotyped judgments against them. Second, self-esteem [16] has been found to be negatively associated with more frequent stigmatizing encounters [3]. A similar decrease in self-esteem might be found among individuals who believe that evaluations of their behaviors are based on their weight. Therefore, we hypothesized that individuals who report higher levels of perceived stereotype threat will report lower self-esteem.

Finally, because overweight/obese individuals are more likely to endorse stereotype threat where the target of the threat is the individual rather than the group, hypothesis three proposed correlates of stereotype threat indicated above (e.g., level of group identity, stereotype endorsement) would be more strongly associated with stereotype threat when the self is the target than for when the group is the target.

\section{Participants and Methods}

\section{Participants}

216 adults were recruited from psychology classes at a large Midwestern university $(n=155 ; 71.8 \%$ of the sample) and the community via the internet (e.g., Facebook and health-related web forums; $\mathrm{n}=61$; 28.1\%). Participants met the study inclusion criteria if they were 18 years or older and were (or perceived themselves to be) overweight or obese. Psychology students were compensated with course credit, and community sample participants received a chance to win a USD 50 or USD 25 Amazon.com gift card. This investigation was approved by the University's institutional review board.

Participants' mean age was 23.6 (SD 10.1; range 18-64) years. The majority of the participants were Caucasian $(81.3 \%)$ and female $(76.1 \%)$. Regarding socioeconomic status, $22.2 \%$ of the sample reported having a high school diploma $(n=48), 64.4 \%$ reported having some college education $(n=139), 6.9 \%$ reported receiving a college diploma $(\mathrm{n}=15)$, and $6.5 \%$ of the sample had a master's degree or higher $(\mathrm{n}=$ 14). Most of the sample earned an annual household income of less than USD 30,000 ( $n=97,45.5 \%)$, with $15.0 \%$ reporting an income between USD 30,000 and USD 45,000 ( $\mathrm{n}=32), 13.1 \%$ earning between USD $45,000$ and USD 60,000 ( $\mathrm{n}=28), 8.9 \%$ earning between USD 60,000 and USD 75,000 ( $\mathrm{n}=19)$, and $17.1 \%$ earning greater than USD 75,000 annually $\left(\mathrm{n}=37\right.$ ). Mean BMI was $31.6 \pm 7.5 \mathrm{~kg} / \mathrm{m}^{2}$ (normal weight (BMI < $\left.25 \mathrm{~kg} / \mathrm{m}^{2}\right) \mathrm{n}=26$; overweight (BMI $\geq 25$ and $<30 \mathrm{~kg} / \mathrm{m}^{2}$ ) $\mathrm{n}=73$; class I obesity (BMI $>30$ and $<40 \mathrm{~kg} / \mathrm{m}^{2}$ ) $\mathrm{n}$ = 94; class II obesity (BMI $\left.>40 \mathrm{~kg} / \mathrm{m}^{2}\right) \mathrm{n}=21$ ). Perception of overweight was assessed with the question: 'Do you consider yourself to be: i) underweight, ii) normal/average weight, iii) overweight, iv) or obese?'. Given that people who perceive themselves as overweight/obese (even if their actual weight is not in the overweight/obese category) may be concerned with confirming negative stereotypes, this investigation included individuals who perceived themselves to be overweight. The vast majority $(92 \%, \mathrm{n}=199)$ of this sample perceived themselves to be overweight or obese and had BMIs $\geq 25$. Of those who perceived themselves to be overweight or obese, 26 (13.7\% of this subsample) did not have a BMI that fell within the overweight or obese categories. However, the findings did not change when participants who perceived themselves to be overweight or obese (but who were not based on their self-reported height and weight) were excluded. Therefore, these participants were included in the analyses. Additionally, a minority of participants ( $8 \%, \mathrm{n}=$ 17) reported that they perceived themselves to be normal weight, but were in fact overweight according to their BMI. Findings did not change when these participants were excluded from analyses and so they were included in analyses. 
Carels et al.: Examining Perceived Stereotype Threat among Overweight/Obese Adults Using a Multi-Threat Framework

\section{Measures}

\section{Perceived Stereotype Threat}

To measure perceived stereotype threat, participants were first asked to identify a negative stereotype associated with obesity that has had an influence on their life by either endorsing one of the six most common stereotypes described by Puhl and Brownell (e.g., laziness, lacking willpower/self-discipline [22]) or generating their own. Next, participants were asked to imagine a situation in which their actions had the potential to confirm the negative stereotype they had just endorsed. Participants were provided a brief example based on the specific negative stereotypes they chose, for example, 'Imagine that you are walking with some acquaintances to a different floor of a building. If you decide to take the elevator instead of the stairs, you may confirm the stereotype that overweight/fat people are lazy.' They were then asked to write a short description of a situation they had personally experienced.

Next, participants completed a 12-item self-report scale designed to measure four types of stereotype threat developed by Shapiro [10]. On a 4-point scale (i.e., not at all; a little; somewhat; a lot), participants reported the extent to which they were concerned that their actions indicated self-concept threat (concern that their actions imply negative things about their own abilities in their own mind, e.g., 'To what extent are you concerned that your actions will lead you to see yourself as actually possessing the negative stereotype that others have about people who are overweight/fat?'), own reputation threat (concern of showing that one's group possesses the negative stereotype, e.g., 'To what extent are you concerned that your actions could lead you to be judged negatively by others because you are overweight/fat?'), group-concept threat (concern about confirming negative stereotypes about the overweight/obese group in their own mind, e.g., 'To what extent are you concerned that your actions will confirm, in your own mind, that the negative stereotypes are true about people who are overweight/fat?'), and group reputation threat (concern of reinforcing other's negative stereotypes of one's group or representing one's group poorly, e.g., 'To what extent are you concerned that your actions will reinforce the negative stereotypes, to others, about people who are overweight/fat?').

We collapsed the categories to simplify analyses and because for this stereotyped group, the source of the threat (self vs. other) is much less relevant than the target of the threat. This is consistent with Shapiro's [11] findings that individuals in low identifying and high stereotype-endorsing groups, such as overweight, were more likely to view themselves, rather than their group, as the target of the threat. Thus, we chose to combine the self-concept and own reputation threat measures to create an overall self/own threat score (6 items; $\alpha=0.88$ ). Similarly, the group-concept and group reputation threat measures were combined to create an overall group threat score ( 6 items; $\alpha=0.87$ ) with higher scores indicating greater threat. The self/own and group threats were correlated at $r=0.72(\mathrm{p}<0.01)$.

\section{Group Identification}

Group identification was measured with eight items modified from the Multigroup Ethnic Identity Measure [17] using a 9-point Likert scale ranging from very strongly agree to very strongly disagree. Factor analyses suggest that the measure has two subscales (affirmation, belonging, and commitment; ethnic search identity). Affirmation, belonging, and commitment were assessed with items, such as 'I have a strong sense of belonging with overweight/fat individuals' and 'I have strong attachment to other overweight/fat individuals'. Group (i.e., ethnic) search identity was assessed with items such as, 'I am active in organizations or social groups that include mostly overweight/fat individuals' and 'I think a lot about how my life is/will be impacted by being an overweight/fat individual'. A total score was calculated with higher scores reflecting higher group identity. Cronbach's $\alpha$ was 0.79 . The sample mean was $29.7 \pm 7.4$.

\section{Stereotype Endorsement}

To measure stereotype endorsement participants were asked to report the extent to which they believe six common stereotypes about overweight/fat people identified by Puhl and Brownell [22] (e.g., I am lazy, I lack willpower/self-discipline) were true of themselves using a 7-point scale ranging from strongly agree to strongly disagree. Higher scores reflected higher stereotype endorsement Cronbach's $\alpha$ was 0.78 for these items. The sample mean was $17.8 \pm 6.2$.

\section{Stigma Consciousness}

Stigma consciousness was measured using a modified version of the Stigma Consciousness Questionnaire [14]. Items were modified to reflect overweight/fat people rather than women. Participants were asked to report the extent to which they agree with ten statements about overweight/fat people (e.g., 'Stereotypes 
Carels et al.: Examining Perceived Stereotype Threat among Overweight/Obese Adults

Using a Multi-Threat Framework

about overweight/fat people have not affected me personally') using a 6-point scale ranging from strongly agree to strongly disagree. Higher scores reflected higher stigma consciousness. Cronbach's $\alpha$ was 0.78 and the mean $3.9 \pm 0.7$.

\section{Anti-Fat Attitudes}

Crandall's Anti-Fat Attitudes Questionnaire [18] was used to assess participant's attitudes toward obesity. This measure contains three subscales: the evaluation and dislike of individuals who are fat (7 items; $\alpha=0.84$ ), the controllability of weight/fat (3 items; $\alpha=0.74$ ), and personal concerns and distress about weight or the prospect of becoming overweight (fear of fat; 3 items; $\alpha=0.83$ ) that are measured on a 10 -point Likert scale ( 0 = very strongly disagree; 9 = very strongly agree) with higher scores indicating stronger anti-fat attitudes. The means for the dislike, controllability of weight, and distress over becoming overweight scales for this sample were $2.4 \pm 1.0,4.3 \pm 1.3$, and $5.2 \pm 1.6$, respectively.

\section{Self-Esteem}

Rosenberg's Self Esteem Scale [19] was used to assess participants' self-esteem. Self-esteem is rated with ten self-report items using a 4-point scale ranging from strongly disagree to strongly agree. Higher scores indicating more positive self-evaluation. Cronbach's $\alpha$ was 0.82 for this study, with a sample mean of $26.3 \pm 5.6$.

\section{Statistical Analyses}

Multivariate analyses of variance were conducted to determine if demographic variables (gender, education, and income) significantly predicted perceived stereotype threat. Bivariate correlations were examined between age and perceived stereotype threat as well. The primary analyses consisted of two parts: examining the level of perceived stereotype threat and evaluating a priori predictors of stereotype threat. For hypothesis one that participants would perceive higher levels of self/own stereotype threat compared to group stereotype threat, a paired samples t-test was conducted. For hypothesis two, the association between stereotype threat and hypothesized predictors were examined using bivariate correlations. For hypothesis three that the predictor variables would be more strongly related to self/own stereotype threat compared to group stereotype threat, dependent $r$ comparisons were conducted [20]. Finally, two additional post-hoc exploratory hierarchical linear regressions were conducted with self/own stereotype threat and group stereotype threat as the dependent variables. For both regressions, gender was entered into step 1 and the following variables were entered into step 2: BMI, group identity, stereotype endorsement, stigma consciousness, fear of fat, and self-esteem.

\section{Results}

\section{Preliminary Analyses}

For demographic variables, MANOVA indicated a significant effect for gender only (F (2, $195)=8.32, \mathrm{p}<0.01)$. As hypothesized, females endorsed significantly higher levels of perceived self/own stereotype threat $(5.80 \pm 3.93)$ compared to males $(3.28 \pm 3.12)$. Similarly, females endorsed significantly higher levels of perceived group stereotype threat $(4.50 \pm 3.60)$ compared to males $(2.52 \pm 2.71)$. Neither education level nor income was significantly associated with perceived stereotype threat. Age was not significantly correlated with either self/own or group stereotype threat. Therefore, gender was entered as a covariate into subsequent analyses.

Participants had been asked to choose one negative stereotype about people with obesity upon which they would base an imagined threatening situation. They chose unattractiveness (44\%), laziness (23\%), lack of willpower (16\%), always binge eats $(14 \%)$, unintelligence $(1 \%)$, poor hygiene $(1 \%)$, or did not respond $(1 \%)$. ANOVA indicated that there was a signif- 


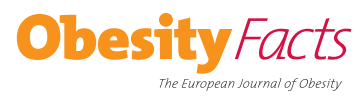

\begin{tabular}{l|l}
\hline Obes Facts 2013;6:258-268 \\
\hline DOI: 10.1159/000352029 & $\begin{array}{l}\text { C } 2013 \text { S. Karger GmbH, Freiburg } \\
\text { www.karger.com/ofa }\end{array}$ \\
\hline $\begin{array}{l}\text { Carels et al.: Examining Perceived Stereotype Threat among Overweight/Obese Adults } \\
\text { Using a Multi-Threat Framework }\end{array}$
\end{tabular}

Table 1. Significantly different correlations among threat targets and related variables

\begin{tabular}{lllllllll}
\hline $\begin{array}{l}\text { Target of } \\
\text { threat }\end{array}$ & $\begin{array}{l}\text { Group } \\
\text { identity }\end{array}$ & $\begin{array}{l}\text { Stereotype } \\
\text { endorsement }\end{array}$ & $\begin{array}{l}\text { Stigma } \\
\text { consciousness }\end{array}$ & $\begin{array}{l}\text { AFA } \\
\text { willpower }\end{array}$ & $\begin{array}{l}\text { AFA } \\
\text { dislike }\end{array}$ & $\begin{array}{l}\text { AFA } \\
\text { fear of fat }\end{array}$ & BMI & Self-esteem \\
\hline Self & $0.40^{*}$ & $0.27^{*}$ & $0.50^{*}$ & 0.07 & 0.03 & $0.40^{*}$ & $0.16^{*}$ & $-0.45^{*}$ \\
Group & $0.29^{*}$ & $0.22^{*}$ & $0.36^{*}$ & 0.08 & 0.05 & $0.25^{*}$ & $0.15^{*}$ & $-0.31^{*}$ \\
Difference & $0.10^{* *}$ & 0.05 & $0.14^{* *}$ & 0.01 & 0.02 & $0.15^{* *}$ & 0.01 & $0.14^{* *}$ \\
\hline
\end{tabular}

* Significant correlation between threat type rating and psychosocial variable, $\mathrm{p}<0.05$.

**Significant difference between correlations in column, $\mathrm{p}<0.05$. Differences between correlations were measured for significance using dependent Rs comparison.

icant difference in self/own threat scores among participants who chose different stereotypes, $\mathrm{F}(5,209)=4.77, \mathrm{p}<0.001$. Using a Bonferroni post-hoc test, participants who chose the unattractiveness stereotype had higher self/own threat scores (5.9) compared to those who chose the always binge eats stereotype (3.8) or the laziness stereotype (3.7).

\section{Main Analyses}

Hypothesis 1: As expected, average self/own perceived stereotype threat (5.2 \pm 3.9$)$ was higher than group stereotype threat $(4.0 \pm 3.5$; $\mathrm{t}(209)=-6.08, \mathrm{p}<0.001)$. These results support the hypothesis that overweight and obese individuals would perceive stereotype threat as an attack against their own reputation or self-concept more so than as a threat against their group.

Hypothesis 2: Most of the predictor variables (group identity, stereotype endorsement, stigma consciousness, fear of fat, and self-esteem) were significantly correlated with self/ own and group perceived stereotype threat (table 1).

Hypothesis 3: To compare the strength of the associations between self/own stereotype threat and predictor variables as well as group stereotype threat and predictor variables, dependent $r$ comparisons were conducted [20]. These indicated a stronger correlation between the predictor variables and self/own threat compared to group stereotype threat (significant differences in strengths of associations are indicated in table 1). For example, the correlation between group identity and self/own threat $(r=0.40, p<0.01)$ was greater than the correlation between group identity and group threat $(r=0.29, p<0.01)$. This pattern of results was found for stereotype endorsement, stigma consciousness, fear of fat, and selfesteem as well.

In addition, post-hoc analyses using regression to examine predictors of self/own stereotype threat, gender emerged as significant predictor $(\beta=0.28, p<0.01)$, accounting for $8 \%$ of the variance in self/own stereotype threat $(\mathrm{F}(1,203)=16.98, \mathrm{p}<0.01)$ in step 1 . The variables entered in step 2 explained an additional $30 \%$ of the variance $(F(7,197)=16.67$, $(\mathrm{p}<0.01)$. Of the variables entered, gender $(\beta=0.12, \mathrm{p}<0.05)$, BMI $(\beta=0.12, \mathrm{p}<0.05)$, stigma consciousness $(\beta=0.21, \mathrm{p}<0.01)$, fear of fat $(\beta=0.19, \mathrm{p}<0.01)$, and self-esteem $(\beta=-0.16$, $\mathrm{p}<0.05$ ) were statistically significant.

Similarly, a hierarchical linear regression was conducted to examine significant predictors of perceived group stereotype threat. In step 1, gender emerged as a significant predictor $(\beta=0.24, p<0.01)$ of perceived group stereotype threat, explaining $6 \%$ of the variance $(F(1$, $203)=12.75, \mathrm{p}<0.01)$. The variables in step 2 explained an additional $14 \%$ of the variance 
Carels et al.: Examining Perceived Stereotype Threat among Overweight/Obese Adults Using a Multi-Threat Framework

$(\mathrm{F}(7,197)=7.16, \mathrm{p}<0.01)$. Of the variables entered, only gender was statistically significant $(\beta=0.15, p<0.05)$, with stigma consciousness showing a trend towards significance $(\beta=0.17$, $\mathrm{p}=0.05)$.

\section{Discussion}

Consistent with the Multi-Threat Framework [11], this investigation sought to examine how different forms of stereotype threat were related to group identity and stereotype endorsement among overweight/obese individuals and those who perceived themselves to be. In addition, we examined the relationship between perceived stereotype threat and factors that hypothetically could be associated with perceived stereotype threat among overweight/obese individuals and those who perceived themselves to be.

As predicted, findings revealed that individuals who are overweight or obese reported a significant history of being threatened by stereotypes related to weight. This is not surprising, given that weight bias is pervasive and increasing [1-4]. Whether real or imagined, the fear that one's actions could lead to harsh judgment or the confirmation of negative stereotypes is a real concern for overweight and obese individuals.

Participants reflecting on past experiences of perceived stereotype threat reported greater levels of self/own stereotype threat compared to group stereotype threat. This is consistent with previous research indicating that the kind of stereotype threat (i.e., self/own versus group) most commonly experienced can vary among stigmatized groups [11]. Specifically, individuals with excess weight are less likely to show an in-group positive bias [18], are less likely to identify with being a part of an overweight group, and thus may be more vulnerable to experiencing threats on the personal or individual level compared to other stigmatized groups [11]. In other words, an obese individual would be generally less concerned that she or he might confirm a negative stereotype about obese people being lazy, and more concerned about having others see him or her as being a lazy person just because they have visible excess weight. Unlike other stigmatized groups with stronger group identity, such as racial minorities, overweight/obese individuals are more concerned that their behaviors will reflect poorly on him- or herself than on obese people in general.

The results of the present study support two of the primary tenets of the Multi-Threat Framework: that the emergence of stereotype threat is strongly associated with group identification (a perceived similarity to other in-group members) and stereotype endorsement (a belief that the stereotype is true). The findings of the present study suggest that, among overweight/obese individuals, those individuals identifying as part of the 'overweight' group and who believe in common stereotypes about overweight individuals were more likely to perceive that stereotype threat had occurred in stigmatizing situations. Interestingly, stronger group identity was associated with greater self/own threat than group threat. At first glance, this finding might appear counterintuitive because it would seem natural for group identity to lead to seeing the group as the target of the threat. However, group identity is both a necessary precondition for threat as well as a factor that influences the perceived target of the threat $[6,11]$. In other words, an individual has to perceive him- or herself as obese and have some level of group identity to experience stereotype threat in the first place. However, it is likely that considerably higher group identity, such as those levels found in racial and religious minorities, would be necessary before an individual was concerned about their group's reputation more than his or her own.

As expected, female participants and participants with higher BMIs reported a greater likelihood of experiencing stereotype threat. As indicated earlier, individuals with higher BMIs and women are more likely to be targets of prejudice and discrimination [4]. In addition, 
Carels et al.: Examining Perceived Stereotype Threat among Overweight/Obese Adults Using a Multi-Threat Framework

weight may hold more self-relevance for females than men. Therefore, women may not only fear but may also be targets of stereotyped evaluations more than men. However, the findings did not change when participants who perceived themselves to be overweight or obese (but who were not based on their self-reported height and weight) were excluded. These findings are consistent with research that revealed few psychological differences in body image, eating/dieting behaviors, and psychosocial well-being between persons as a function of their perceived versus actual weight [21].

Being aware of and believing their stereotyped status (i.e., stigma consciousness) was also related to higher levels of perceived stereotype threat. Not surprisingly, as stigma consciousness increased, participants reported a greater perception that they had experienced self/own stereotype threat compared to group stereotype threat. These findings are consistent with previous research examining stigma consciousness and stereotype threat among women in the math domain. Brown and Pinel [15] showed that inducing stereotype threat in a group of women, who also endorsed high levels of stigma consciousness, resulted in domain-specific performance deficits (i.e., lower scores on math tests). These findings would appear to generalize to overweight/obese individuals. The more individuals are aware of stereotypes, believe in them, and find that they pervade their life experiences, the more likely they are to experience stereotype threat.

Additionally, possessing a fear of being fat was related to higher levels of perceived stereotype threat. Previous research suggests that overweight and obese people frequently hold strong anti-fat (i.e., anti-group) attitudes $[4,11]$ which is in contrast to other stigmatized groups who are less likely to endorse within-group stereotypes. It is likely that the heightened sensitivity to being overweight/obese contributed to a greater fear of judgment. Overweight/ obese individuals who feared their overweight group status were more likely to perceive stereotyped judgments were directed against them.

Finally, experiencing low self-esteem was related to higher levels of stereotype threat. Self-esteem has been found to be negatively related to the greater frequency of stigmatizing situations [3]. People with more frequent past experiences with weight-based discrimination may be more vigilant to having their behaviors judged relative to their weight. Therefore, low self-esteem may be a consequence of experiencing stereotype threat. Future research will be important in answering this question.

Taken together, the results from this investigation provide support for the Multi-Threat Framework for stereotype threat broadly, but also specifically related to overweight and obese individuals. Both self/own and group stereotype threat were reported by overweight individuals (and as expected, self/own stereotype threat was reported to a greater extent). Additionally, the two types of stereotype threat are related to a number of personal characteristics (i.e., gender, BMI) and individual factors (i.e., group identity, stigma consciousness, fear of fat). However, there are some limitations of the present study, along with implications for future research that are important to note. First, although the primary focus of the study related to participants' weight and perceptions of weight-related stereotype threat, some participants endorsed belonging to a variety of other stigmatized groups (e.g., gender, racial/ ethnic, etc.). However, given that the current sample was composed primarily of Caucasians $(81.3 \%)$ and members of a religious majority $(76.1 \%)$, inadequate statistical power limited our ability to examine interactions between identification with another stigmatized group and weight-related stereotype threat.

A second limitation of the present study is that findings are based on participants' selfreports of perceived stereotype threat; behavioral outcomes of being threatened with negative stereotypes (i.e., performance deficits) were not measured. With this method, we were not able to assess the direct outcomes of experiencing weight-related stereotype threat on domain-specific functioning. However, prior research has found participants' self-reported 
Carels et al.: Examining Perceived Stereotype Threat among Overweight/Obese Adults

Using a Multi-Threat Framework

stereotype threat experiences to parallel performance outcomes. In particular, individuals' self-reports of stereotype threat in other stigmatized groups (e.g., race) are associated with negative implications for related performance outcomes [e.g., 24-27]. Finally, although the findings from this investigation are consistent with theoretical predictions from the MultiThreat Framework, we cannot rule out the possibility that the instructions to the participants 'to identify a negative stereotype associated with obesity that has had an influence on their life' differentially favored their selection of a threat for which self rather than others were the source of the target.

The current findings provide a base on which to build future research designed to measure the direct effects of experiencing weight-related stereotype threat through experimental manipulation of each type of threat (e.g., threats to the self vs. the group). This research will be necessary to definitively say that weight-based stereotype threat is a valid phenomenon. Future research could examine how performance on tasks related to health decision-making or physical activity effort is affected by the presentation of negative weight-related stereotypes. Burgess, et al. [28] outlined a number of ways in which patients' experience of stereotype threat in clinical settings and encounters may contribute to health care disparities. To our knowledge only one study has examined stereotype threat among obese adults. Seacat and Mickelson [10] found that overweight women who were exposed to negative weight-related stereotypes reported fewer healthy dietary and exercise intentions compared to a control. Additionally, in similar research on social identity threat, Major et al. [29] found that overweight women who were exposed to appearance related evaluations (i.e., rated on a speech on why they would make a good dating partner) and who believed that they were being videotaped, exhibited increased blood pressure, diminished executive control, and more stressrelated emotions compared to average-weight women.

The present study provides an important evaluation of the Multi-Threat Framework [6, 11] for stereotype threat in overweight and obese individuals. This research adds to the understanding of how stereotypes may affect overweight individuals, a group known to experience a high degree of stigma and weight bias [4]. A greater understanding of how stereotype threat affects individuals who are overweight could lead to the development of interventions to ameliorate likely negative psychosocial and health behavior outcomes.

\section{Disclosure Statement}

The authors declare no conflict of interests.

\section{References}

1 Friedman KE, Reichmann SK, Costanza PR, Zelli A, Ashmore JA, Musante GJ: Weight stigmatization and ideological beliefs: relation to psychological functioning in obese adults. Obesity (Silver Spring) 2005;13:907-916.

-2 Guyll M, Matthews KA, Bromberger JT: Discrimination and Unfair treatment: relationship to cardiovascular reactivity among African American and European American women. Health Psychol 2001;20:315-325.

-3 Myers A, Rosen JC: Obesity stigmatization and coping: relation to mental health symptoms, body image, and self-esteem. Int J Obes 1999;25:1525-1531.

4 Puhl, R. M. and Heuer, C. A. The Stigma of Obesity: A Review and Update. Obesity 2009;17(5):1-24.

5 Puhl RM, Moss-Racusin CA, Schwartz MB, Brownell KD: Weight stigmatization and bias reduction: perspectives of overweight and obese adults. Health Educ Res 2008;23:347-358.

-6 Shapiro JR, Neuberg SL: From stereotype threat to stereotype threats: implications of a multi-threat framework for causes, moderators, mediators, consequences, and interventions. Pers Soc Psychol Rev 2007;11:107-130.

7 Steele CM, Aronson J: Stereotype Threat and the intellectual test-performance of African-Americans. J Pers Soc Psychol 1995;69:797-811. 
Carels et al.: Examining Perceived Stereotype Threat among Overweight/Obese Adults Using a Multi-Threat Framework

8 Schmader T, Johns M, Forbes C: An integrated process model of stereotype threat effects on performance. Psychol Rev 2008;115:336-356.

-9 Schmader T, Johns M: Converging evidence that stereotype threat reduces working memory capacity. J Pers Soc Psychol 2003;85:440-452.

10 Seacat JD, Mickelson KD: Stereotype threat and the exercise/ dietary health intentions of overweight women. J Health Psychol 2009; 14:556-567.

11 Shapiro JR: Different groups, different threats: a multi-threat approach to the experience of stereotype threat. Pers Soc Psychol Bull 2011;37:464-480.

-12 Ashmore RD, Deaux K, McLaughlin-Volpe T: An organizing framework for collective identity: articulation and significance of multidimensionality. Psychol Bull 2004;130:80-114.

13 Quinn DM, Crocker J: Vulnerability to the affective consequences of the stigma of overweight; in Swim JK, Stangor C (eds): Prejudice: The Target's Perspective. San Diego, Academic Press, 1998, pp 125-143.

14 Pinel EC: Stigma consciousness: the psychological legacy of social stereotypes. J Pers Soc Psychol 1999;76: 114-128.

15 Brown RP, Pinel EC: Stigma on my mind: individual differences in the experience of stereotype threat. J Exp Soc Psychol 2003;39:626-633.

16 Hewitt J P: Oxford Handbook of Positive Psychology. New York, Oxford University Press, 2009.

17 Phinney JS: The Multigroup Ethnic Identity Measure: a new scale for use with diverse groups. J Adolesc Res 1992; 7:156-176.

18 Crandall CS: Prejudice against fat people: ideology and self-interest. J Pers Soc Psychol 1994;66:882-894.

19 Rosenberg M: Self-esteem scale; in Robinson JP, Shaver PR (eds): Measures of Social Psychological Attitudes. Ann Arbor, Survey Research Center for Social Research, 1983, pp 81-83.

20 Cohen J, Cohen P, West SG, Aiken LS: Applied Multiple Regression/Correlation Analysis for the Behavioral Sciences. Mahwah, L. Erlbaum Associates, 2002.

21 Cash TF, Higgins ET: Being fat versus thinking fat: relationships with body image, eating behaviors, and wellbeing. Cogn Ther Res 1990;14:327-341.

22 Spencer SJ, Steele CM, Quinn DM: Stereotype threat and women's math performance. J Exp Soc Psychol 1999; 35:4-28.

23 Bosson JK, Haymovitz EL, Pinel EC: When saying and doing diverge. J Exp Soc Psychol 2004;40:247-255.

24 Cohen GL, Garcia J: 'I Am Us': negative stereotypes as collective threats. J Pers Soc Psychol 2005;89:566-582.

25 Goff PA, Steele CM, Davies PG: The space between us: stereotype threat and distance in interracial contexts. J Pers Soc Psychol 2008;94:91-107.

26 Marx DM, Ko SJ, Friedman RA: The 'Obama effect': how a salient role model reduces race-based performance differences. J Exp Soc Psychol 2009;45:953-956.

27 Marx DM, Goff PA: Clearing the air: the effect of experimenter race on target's test performance and subjective experience. Br J Soc Psychol 2005;44:645-657.

-28 Burgess DJ, Warren J, Phelan S, Dovidio JF, van Ryn M: Stereotype threat and health disparities: what medical educators and future physicians need to know. J Gen Intern Med 2010;25(suppl 2):S169-S177.

29 Major B, Eliezer D, Rieck H: The psychological weight of weight stigma. Soc Psychol Pers Sci 2012;3:651-658 